\title{
Spatiotemporal changes in frequency and intensity of high-temperature events in China during 1961-2014
}

\author{
ZHANG Ming 1, "DU Shiqiang1, "WU Yanjuan"2,1, WEN Jiahong ${ }^{1}$, WANG Congxiao', \\ XU Ming ${ }^{3}$, WU Shuang-Ye ${ }^{4}$ \\ 1. Department of Geography, Shanghai Normal University, Shanghai 200234, China; \\ 2. Key Laboratory of Watershed Geographic Sciences, Nanjing Institute of Geography and Limnology, CAS, \\ Nanjing 210008, China; \\ 3. Shanghai Typhoon Institute, China Meteorological Administration, Shanghai 200030, China; \\ 4. Department of Geology, University of Dayton, Dayton OH 45469, USA
}

\begin{abstract}
In this study, we explored spatial patterns and the temporal trends in high-temperature events (HTEs) for the mainland of China during 1961-2014 based on a daily- maximum surface-air-temperature dataset of 494 stations and nonparametric trend detection methods. With three thresholds of $35^{\circ} \mathrm{C}$ (HTE35), $37^{\circ} \mathrm{C}$ (HTE37), and $40^{\circ} \mathrm{C}$ (HTE40), HTEs occurred in $82 \%, 71 \%$, and $37 \%$ of the surveyed stations and showed an overall increasing trend in both frequency and intensity during 1961-2014. In northern and southeastern China, HTEs showed a significant increasing trend in both frequency and intensity, whilst a decreasing trend for both was observed in central China. Despite such regional heterogeneity, HTEs overwhelmingly presented three-phase characteristics in all three representative regions and throughout China; the phases are 1961-1980, 1980-1990, and 1990-2014. Both frequency and intensity of HTEs have strongly increased during 1990-2014 at 54.86\%, $48.38 \%$, and $23.28 \%$ of the investigated stations for HTE35, HTE37 and HTE40, respectively. These findings implied that HTEs adaptation should be paid further attention in the future over China because the wide spread distribution of HTEs and their increasing trends in both frequency and intensity during recent decades might pose challenges to the sustainability of human society and the ecosystem.
\end{abstract}

Keywords: high temperature; heat waves; extreme events; climate change; hiatus; warming hole

\section{Introduction}

A high-temperature event (HTE) is a natural hazard that occurs when temperature exceeds a threshold, i.e. $35^{\circ} \mathrm{C}, 37^{\circ} \mathrm{C}$, and $40^{\circ} \mathrm{C}$ (CMA, 2008). HTEs can seriously affect various as-

Received: 2016-08-16 Accepted: 2017-02-24

Foundation: National Natural Science Foundation of China, No.41401603

Author: Zhang Ming (1989-), Master, specialized in meteorological disasters and climate change.

E-mail: zhangminggeo@126.com

"Corresponding author: Du Shiqiang (1984-), Associate Professor, E-mail: shiqiangdu@shnu.edu.cn;

Wu Yanjuan (1989-), PhD, E-mail: wuyanjuanfree@sina.cn 
pects of human society and the ecosystem, e.g., human health, energy consumption, labor productivity, precipitation, and hydrological processes (Davis and Gertler, 2015; Portmann et al., 2009; Zander et al., 2015). Because of an HTE in Europe in 2003, more than 70,000 people died across European countries and crop losses were estimated to be approximately US\$ 12 billion (Robine et al., 2008). In 2013, a HTE-related drought caused direct economic loss of nearly US\$ 10 billion in China (Hou et al., 2014). Moreover, HTEs may change in both intensity and frequency in the context of global climate change and urbanization.

The intensity and frequency of HTEs have shown complicated spatial patterns and temporal trends worldwide (Donat et al., 2013; Hansen et al., 2012). On one hand, global warming has been argued to probably cause increases in HTEs (IPCC, 2012). For example, Hansen et al. (2012) showed that the areas impacted by HTEs have expanded globally since 1981. Moreover, HTEs are probably enhanced by urban heat islands in the process of accelerated urbanization (Sun et al., 2014; Zhou et al., 2004). On the other hand, both temporal and spatial heterogeneity were found in the trends of mean temperature and HTEs (Donat et al., 2013). Temporally, a phenomenon called "hiatus" slowed down global warming after 1998 (Easterling and Wehner, 2009; Karl et al., 2015), which may have affected the frequency and intensity of HTEs (Donat et al., 2013). Spatially, "warming holes" were revealed in the southeastern United States (Donat et al., 2013; Meehl et al., 2012) and central China (Pan et al., 2013) that showed cooling trends in the summer mean temperature in the second half of the 20th century. Complicated spatial patterns and temporal trends of HTEs were therefore expected with the combination of global warming, urban heat islands, hiatus, and the warming hole.

HTEs are attracting increasing attention in China; however, different conclusions have been reached regarding HTEs' variations over space and time (Ding et al., 2010; Pan et al., 2013; Sun et al., 2014). For example, Wang et al. (2014b) showed an increasing trend in both frequency and intensity of HTEs in northern China; in contrast, a decreasing trend of HTEs was found both in northern China (Zhang et al., 2004) and throughout China (Zhai and Pan, 2003) during 1951-1999. Wang et al. (2014b) concluded that HTEs had different temporal phases, e.g., high frequency in the 1960s, low frequency in the 1970s and 1980s, and high frequency in the 1990s and 2000s. However, different temporal modes were found in other regions, e.g., northwestern China (Ding et al., 2010), and Three Gorges area (Deng et al., 2012). Thus, contrasting conclusions exist regarding the spatial distribution and temporal change of HTEs.

These differences were mainly caused by the different standards used for defining an HTE. Previous studies used both the 90th percentile of the daily maximum temperature (Piao et al., 2010; Wang et al., 2014b) and $35^{\circ} \mathrm{C}$ (Ding et al., 2010; Sun et al., 2014; Zhai and Pan, 2003; Zhang et al., 2004) as the threshold for an HTE. According to Zhang et al. (2011), percentile-based temperature indices can ensure an adequate sample size for statistical analyses but are likely to only reflect "moderate extremes"; moreover, such indices are subject to sampling uncertainty and result in spatial inconsistency. In contrast, absolute indices may be more suitable for impact analyses and regional comparison (Zhang et al., 2011). Absolute indices are, therefore, necessary to be employed for understanding the possible impacts and regional variations of HTEs in China (Deng et al., 2011). However, the value of $35^{\circ} \mathrm{C}$ has been used as a sole threshold of HTE in previous studies in China (Ding et al., 2010; Liu et 
al., 2015; Sun et al., 2014; Zhai and Pan, 2003; Zhang et al., 2004).

As mentioned above, three shortcomings still exist against a comprehensive understanding of HTEs in China, despite the merits of recent studies. First, existing studies have only paid attention to HTEs exceeding $35^{\circ} \mathrm{C}$ when using absolute indices of HTEs; multi-threshold HTEs have not yet been examined. Second, few studies have investigated both the frequency and intensity of HTEs. Third, a knowledge gap still exists in the patterns and trends of HTEs in the context of asymmetric warming (e.g., "warming hole" and "hiatus"). The present paper aims to overcome these shortcomings through examining the spatiotemporal patterns of HTEs' frequency and intensity across China during 1961-2014 in the context of asymmetric warming. First, it develops indices of intensity and frequency of multi-threshold HTEs and investigates spatial patterns in these indices in stations across China. Second, it analyzes the magnitude and significance of trends in these indices through the weighted Sen's slope and Mann-Kendell (MK) test, respectively. Third, it produces time series of those HTE indices throughout China and in representative regions through the area-weighted average and examines the possible temporal asymmetries in those HTE indices via the locally weighted regression (LOESS).

\section{Data and indices}

\subsection{Meteorological dataset}

The daily-maximum surface-air-temperature dataset during 1961-2014 was provided by the National Climate Center (NCC) of the China Meteorological Administration (CMA). This dataset has gone through the strict quality control procedures and has also been widely used in studying climate changes in China (Li et al., 2015; Shi et al., 2016). Only the daily maximum temperature of summer, defined as June-August, was employed because HTEs occurred very rarely in other seasons. To avoid bias in trend analyses due to missing data and enhance the temporal consistency in time series of daily temperature, 260 stations that had one or more missing records in the summer dataset of daily maximum temperature during 1961-2014 were excluded. The final dataset covered 494 stations, as shown in Figure 1.

\subsection{High-temperature indices}

High-temperature indices were developed according to the standards of heat-warning alerts designed by the China Meteorological Administration (CMA). Three-grade warning alerts are announced by NWS based on 24-hour temperature forecasts when the maximum temperature is expected to reach $35^{\circ} \mathrm{C}$ (yellow alert), $37^{\circ} \mathrm{C}$ (orange alert), and $40^{\circ} \mathrm{C}$ (red alert). With the alerts come a series of corresponding responses, e.g., a reduction in outdoor activities; protection to outdoor workers; assistance to infants, disabled, and elders; and protection to critical facilities. Accordingly, this study defined HTEs of three grades based on the 24-hour maximum temperature. HTEs was named HTE35, HTE37, and HTE40 when the 24-hour maximum temperature reached $35^{\circ} \mathrm{C}, 37^{\circ} \mathrm{C}$, and $40^{\circ} \mathrm{C}$, respectively. HTEs' frequencies (HTEf) and intensities (HTEi) were calculated for each station by using the following equations:

$$
\begin{gathered}
\operatorname{HTEf}(j, k)=\sum_{i=1}^{n} \operatorname{logical}\left(t_{i, j}-S_{k}\right) \\
\operatorname{HTEi}(j, k)=\sum_{i=1}^{n}\left(t_{i, j}-S_{k}\right) / \operatorname{HTEf}(j, k)
\end{gathered}
$$


where $\operatorname{HTEf}(j, k)$ and $\operatorname{HTEi}(j, k)$ refer to the frequency and intensity in the year $j$ for grade- $k$ HTE, respectively; $i$ and $j$ indicate date and year, respectively; $t_{i, j}$ is the maximum temperature for date $i$ in year $j ; k$ indicates three HTE grades corresponding to the thresholds for HTEs, $S_{k}$, namely $35^{\circ} \mathrm{C}, 37^{\circ} \mathrm{C}$, and $40^{\circ} \mathrm{C}$; logical $\left(t_{i, j}-S_{k}\right)$ is 0 when $t_{i, j}<S_{k}$ or 1 otherwise. On this basis, six HTE indices were developed as the three-grade HTE's frequencies-HTE f35, HTE f37, and HTE f40 — and intensities-HTE i35, HTE i37, and HTE i40.

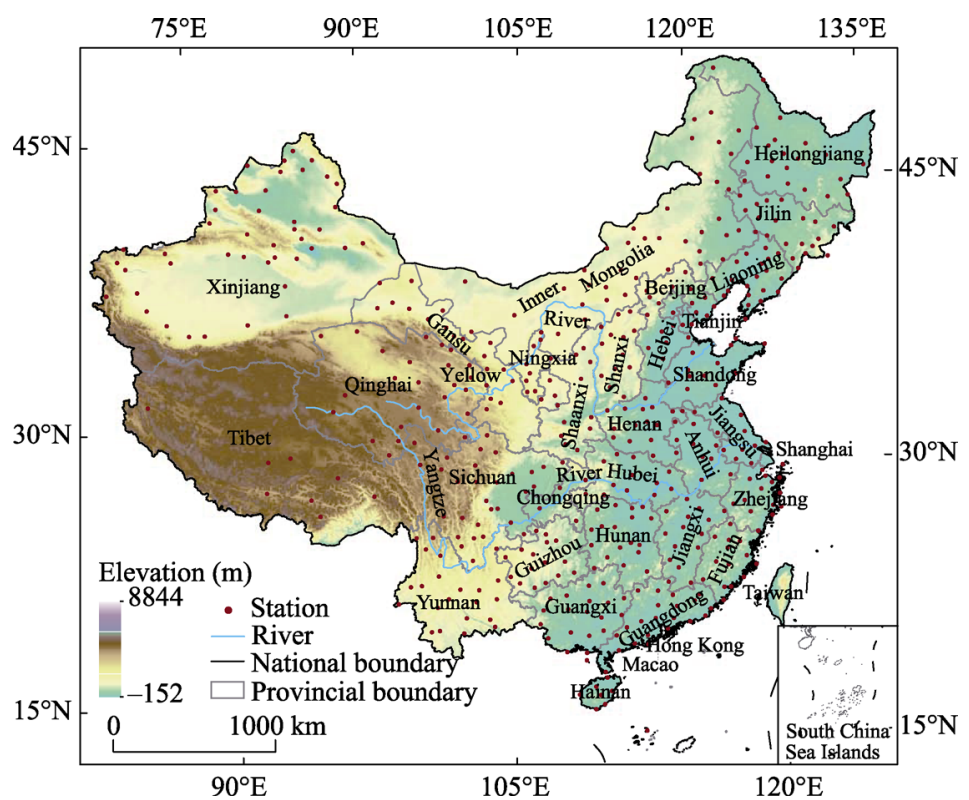

Figure 1 Distribution of the meteorological stations, main rivers, elevation, and provincial boundaries of China

\section{Methodology}

This study investigated trends in the frequencies and intensities of HTEs at two levels, namely station level and regional level. First, it assessed the station-level trends in indices and corresponding significance through the weighted Thiel-Sen's slope (Wu et al., 2016) and Mann-Kendall (MK) test (Kendall, 1975; Mann, 1945). Second, three representative regions are selected based on the station-level occurrence and trends in both indices and the biophysical zonation of China and then produced regional time series of both indices by using the grid-area weighted average (GAWA) method (Jones and Hulme, 1996). Additionally, the temporal characteristics of these time series were examined using a robust locally weighted regression (LOESS) (Cleveland, 1979).

\subsection{Trend analysis}

\subsubsection{Sen's slope estimator}

The Thiel-Sen's slope is a nonparametric method that estimates the sign and magnitude of a trend in a time series (Li et al., 2015). It does not require samples to follow a specific distribution and can perform well even when there are a few anomalous values (Alexander et al., 2006; Sen, 1968). It has been widely applied as an effective method to evaluate trends in extreme-climate indices (Alexander et al., 2006; Donat et al., 2013; Peterson et al., 2008). This method first calculates the slope between any two points in the time series $\left(X=x_{1}, \ldots\right.$ 
$\left.x_{j}, \ldots x_{k}, \ldots, x_{n}\right)$ as follows:

$$
S_{j k}=\left(x_{j}-x_{k}\right) /(j-k)
$$

where $S_{j k}$ is the slope between data points $x_{j}$ and $x_{k} ; j-k$ represents the temporal length between data points $x_{j}$ and $x_{k}(j>k)$. In this manner, this method produces a series of $S_{j k}$. It then calculates the median of the series of $S_{j k}$ as the Sen's slope estimator of the original time series $X$.

However, this method can be problematic when many ties exist in the data, i.e., when $x_{j}=x_{k}$, yielding many slopes of zero. This could occur in count-based data (e.g., HTEs' frequency and intensity variables) or areas where many observations were zero. In these cases, the Thiel-Sen's slope could be zero even when other methods, e.g., the Mann-Kendall test, detect a statistically significant non-zero trend. In order to counter this problem, Wu et al. (2016) introduced a weighted-average Sen's slope estimator based on the assumption that pairs of samples with greater differences in x-coordinates (years) are more likely to have an accurate slope and, therefore, should receive a greater weight (Sievers, 1978). Therefore, the Thiel-Sen slope was rectified by a weight for all $S_{j k}$ to generate an average estimator for the long-term trend of the time series ( $\mathrm{Wu}$ et al., 2016). The weighted trend (ws) is defined as follows:

$$
w s=\sum w_{j k} \times S_{j k}
$$

where

$$
w_{j k}=\frac{\left(x_{j}-x_{k}\right)^{2}}{\sum\left(x_{j}-x_{k}\right)^{2}}
$$

\subsubsection{MK test}

The MK test is a non-parametric method that can reveal the significance of a trend in time series (Kendall, 1975; Mann, 1945). As a method robust to anomalies, it has been widely applied in hydro-meteorological time series (Alexander et al., 2006; Donat et al., 2013; Peterson et al., 2008). In this method, the MK $Z$ statistic follows a standard normal distribution and can indicate the significance of a trend (Wang and Swail, 2001). In this study, a significance level of $5 \%$ (the absolute value of $Z \geqslant 1.96$ ) was used to determine the significance of a trend for a single station against the null hypothesis that no significant trend exists in the station's times series.

\subsubsection{Serial correlation}

According to previous studies (Wang and Swail, 2001), climatic data are somehow correlated in time. Therefore, the MK test and Sen's slope estimator encounter a problem in detecting a significant trend in serially correlated data (Alexander et al., 2006; Peterson et al., 2008). Autocorrelation existed for stations with HTE f35 (39.7\%), HTE i35 (44.7\%), HTE f37 (28.5\%), HTE i37 (33.6\%), HTE f40 (4.2\%), and HTE i40 (6.7\%). Thus, pre-whitening was applied before the MK test and weighted Sen's slope estimator to these time series of HTE indices for removing serial correlation. Detailed information on the pre-whitening procedure can be found in Wang and Swail (2001).

\subsection{High-temperature time series}

The regional time series of HTEs were computed using the grid-area weighted method 
(Jones and Hulme, 1996). This method is simple and reliable for estimating regional time series based on point datasets (e.g., station-based HTEs) and has been widely used in regional time series analyses (Li et al., 2015). It first calculates the simple average of data in stations within a grid (e.g., $2^{\circ}$ by $2^{\circ}$ grid) for a given year. It then generates an area-weighted average of all grid-simple averages as the regional value for the given year (Li et al., 2015). The calculation is as follows:

$$
X_{k}=\frac{\sum_{i=1}^{m} w_{i} \times X_{i k}}{\sum_{i=1}^{m} w_{i}}=\frac{\sum_{i=1}^{m} \cos (\text { lat } i) \times X_{i k}}{\sum_{i=1}^{m} \cos (\text { lat } i)}
$$

where $X_{k}$ represents the regional average at a given year $k ; w_{i}$ is the weight for grid $i$ that is represented by cosine value of the central latitude of grid $i-\cos ($ lat $i) ; X_{i k}$ is the simple average of the data in stations within grid $i$.

\subsection{Local weighted regression}

In order to show decadal or longer-time-scale variations and trends, we used a robust locally weighted regression algorithm (LOESS) (Cleveland, 1979). The LOESS does not require the specification of a function to fit a model. Hence, no assumptions need to be made about the distribution of data, which is often problematic with daily climate data. The LOESS has been proved to be a good choice for reducing the influence of anomalous values on the trend, and it allows for a temporal-explicit trend curve (Peterson et al., 2008).

\section{Results}

\subsection{Spatial distributions of HTE frequency and intensity}

The three HTEs varied over space in both frequency and intensity (Figure 2). The HTEs were low in both frequency and intensity for all the three types in the mountainous and elevated southwest China (Tibet, Qinghai, west Sichuan, and Yunnan), except for a few stations. This region was, therefore, excluded from further analyses in this paper. In contrast, other regions had much higher HTEs, and the corresponding magnitudes were much greater. However, clear variations occurred in those regions as well.

HTE35 occurred in $82 \%$ of the surveyed stations (403/494) and with a frequency greater than once per year in 58\% of the stations (286/494) (Figure 2a). In the belt between Gansu and Heilongjiang, the annual HTE35 frequencies were mostly less than 3 per year. In northwest (mainly Xinjiang) and southeast China, HTE35s occurred frequently. Here, the frequencies mostly ranged from 12 to 24 per year, while dozens of stations in the mid-lower reaches of the Yangtze River and Xinjiang had 24 or more HTE35s per year, among which seven stations had 36 or more HTE35s per year. The HTE35 intensity had different spatial patterns from that of HTE35 frequencies (Figure 2b). Most stations that experienced HTE35s had an average intensity of $36.0-36.5^{\circ} \mathrm{C}$. The stations with average intensities less than $36^{\circ} \mathrm{C}$ were mainly distributed in northeast China, the upper-middle reaches of the Yellow River, the middle reaches of the Yangtze River, and eastern and southern coastal regions. The stations with average intensities greater than $37^{\circ} \mathrm{C}$ were located in Xinjiang and the mid-lower reaches of the Yangtze River.

The distribution of HTE37s is significantly less than that of HTE35s (Figure 2c). HTE37s occurred in $71 \%(349 / 494)$ of all the stations, two thirds of which had frequencies less than 
3 per year. The stations with 3-6 HTE37s annually were distributed in the lower reaches of the Yellow River, mid-lower reaches of the Yangtze River, and Xinjiang. The stations with more than 6 HTE37s per year were mainly distributed in Xinjiang and the mid-lower reaches of the Yangtze River; two stations in Xinjiang had more than 24 HTE37s per year. The average intensity of HTE37s mainly ranges from $37.0^{\circ} \mathrm{C}$ to $38.5^{\circ} \mathrm{C}$ (Figure $2 \mathrm{~d}$ ). There were approximately half of the stations to the north of the Yangtze River had average intensities of $38.0-39.0^{\circ} \mathrm{C}$; while the average intensity mainly ranged from $37.0^{\circ} \mathrm{C}$ to $38.0^{\circ} \mathrm{C}$ for stations in the reaches of the Yangtze River and to its south. Only about 37\% (181/494) of the

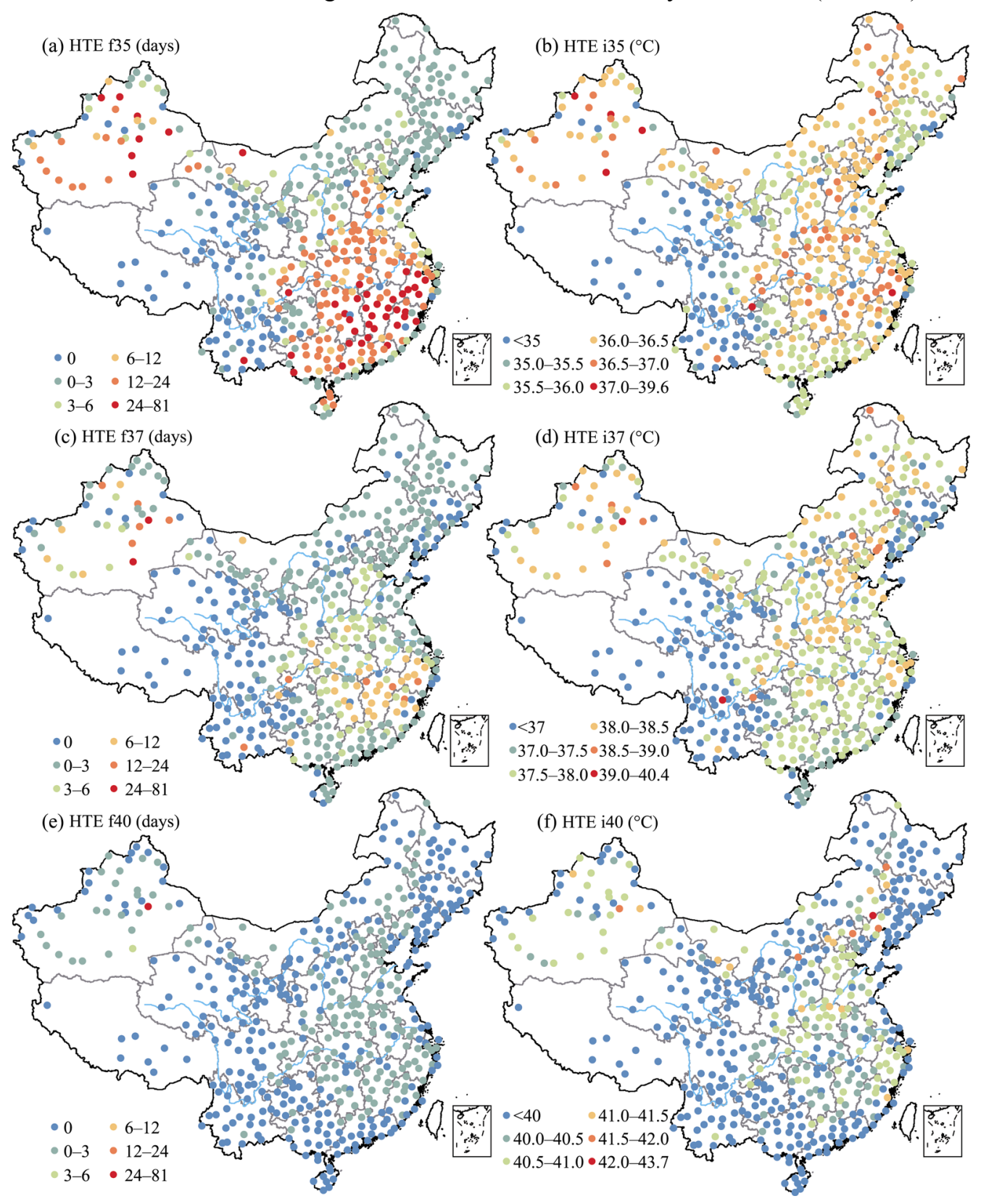

Figure 2 Annual frequencies (a, c, e) and mean intensities (b, d, f) during 1961-2014 of HTE35, HTE37, and HTE40 
stations experienced HTE40s, and they were mainly distributed in Xinjiang and the mid-lower reaches of the Yellow River and Yangtze River (Figure 2e). Most of these stations had less than 3 HTE40s per year, while two stations in Xinjiang experienced more than 3 HTE40s annually. Similar to the intensities of HTE37s, stations that had higher average intensities of HTE40s (e.g. $>41^{\circ} \mathrm{C}$ ) were mainly located in northern China, e.g. Xinjiang, Gansu, Shanxi, Henan, Hebei, Liaoning, and Jilin (Figure 2f).

\subsection{Trends in HTE frequency and intensity}

Spatially varied trends were observed in annual frequency and mean intensity of the three-threshold HTEs during 1961-2014 (Figure 3). Overall, stations in southwest China did not show observable trends in HTE frequency or intensity for all the three-level HTEs. Most stations showed increasing trends in both HTE frequency and intensity while declining trends were mainly observed in the mid-lower reaches of the Yellow River.

HTE35 increased in frequency and intensity for most stations that witnessed HTE35 (Figures $3 \mathrm{a}$ and $3 \mathrm{~b}$ ). The frequency of HTE35 increased at 323 stations (65\% of all stations) and its intensity increased at 296 stations ( $60 \%$ of all stations), among which 271 stations (55\% of all stations) showed increasing trends in both frequency and intensity. Further, significant increasing trends $(p<0.05)$ were detected in frequency at 95 stations $(19 \%$ of all stations) in intensity at 69 stations (14\% of all stations), and in both frequency and intensity at 55 stations (11\% of all stations). The strongest increasing trends in HTE35 frequency and intensity occurred in Xinjiang, Inner Mongolia, Yangtze River Delta, and Pearl River Delta. Their rates of increase in frequency and intensity can be as high as 5.5 days/10a and $0.24^{\circ} \mathrm{C} / 10 \mathrm{a}$, respectively. In contrast, decreasing trends in HTE35 frequency and intensity were mainly detected in the mid-lower reaches of the Yellow River, and the distribution was relatively limited. HTE35 decreased in frequency at 80 stations (16\% of all stations) and in intensity at 107 stations ( $22 \%$ of all stations), among which 55 stations (or $11 \%$ all stations) showed decreasing trends in both frequency and intensity. Only two stations had significant decreasing trends of HTE35 in both frequency and intensity.

HTE37 showed a spatial pattern similar to that of HTE35 in both frequency and intensity. Increasing trends were detected to the north of the Yellow river and to the south of the Yangtze River, while decreasing trends were mainly found in the mid-lower reaches of the Yellow River. The strongest increasing trends of HTE37 in frequency and intensity were detected in Xinjiang, Inner Mongolia, Yangtze River Delta, and Pearl River Delta. Their rates of increase in frequency and intensity were as high as 4.17 days $/ 10 \mathrm{a}$ and $0.23^{\circ} \mathrm{C} / 10 \mathrm{a}$, respectively. Increasing trends were detected at 266 stations (54\%) in HTE37 frequency, at 265 stations (54\%) in HTE37 intensity, and at 239 stations in both indices. Among these stations, significant increasing trends were detected at 47 stations in frequency, at 33 stations in intensity, and at 29 stations in both indices $(p<0.05)$. In contrast, decreasing trends were detected only at 83 stations in frequency, at 84 stations in intensity, and at 57 stations in both indices. Among them, significant trends were detected only at four stations in frequency, at two stations in intensity, and at two stations in both indices.

The HTE40 increased at 123 stations for frequency, at 126 stations for intensity, and at 115 stations for both indices. These stations were mainly located to the north of the Yellow River and to the south of the Yangtze River. Among them, significant increasing trends were 


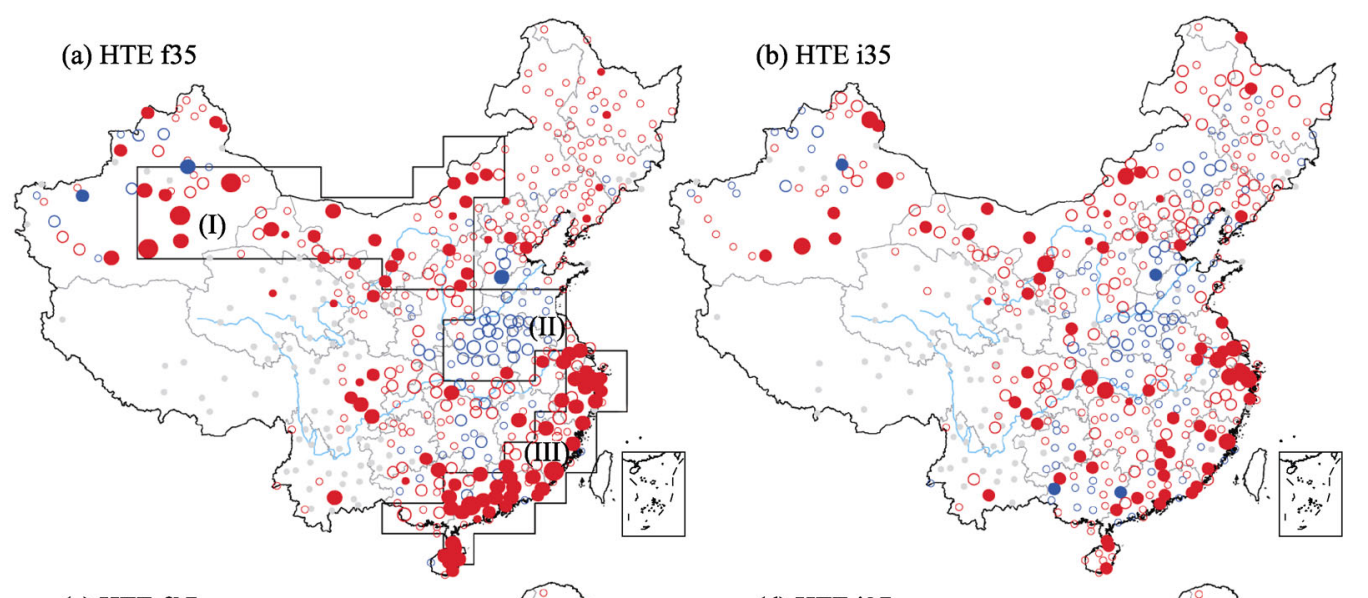

(a) HTE f37

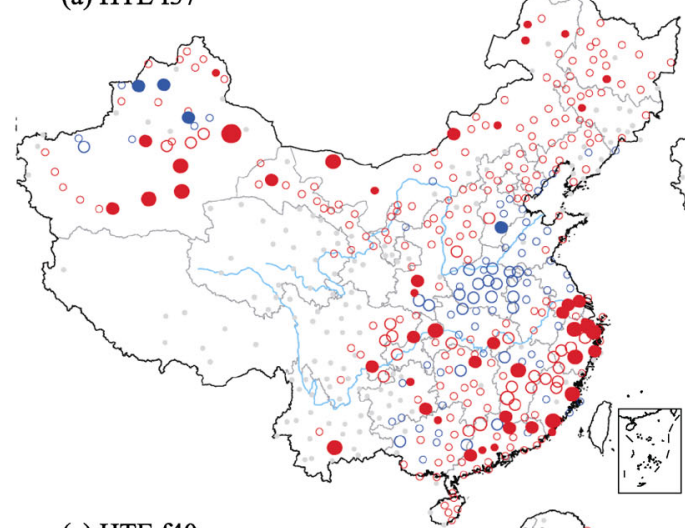

(d) HTE i37

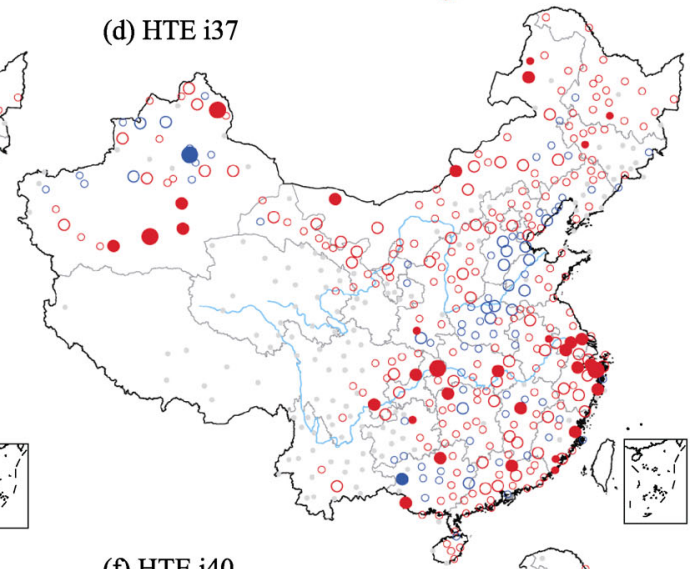

(e) HTE f40

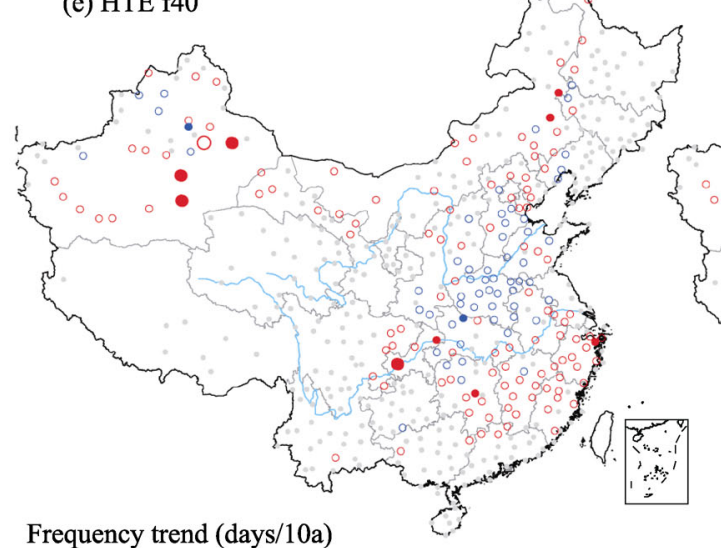

$0-2.5--1.5 \circ-0.5-0 \circ 0.5-1.5$

$\circ-1.5--0.5 \circ 0-0.5 \quad \circ 1.5-4 \quad \bigcirc 4-5.5$

(f) HTE i40

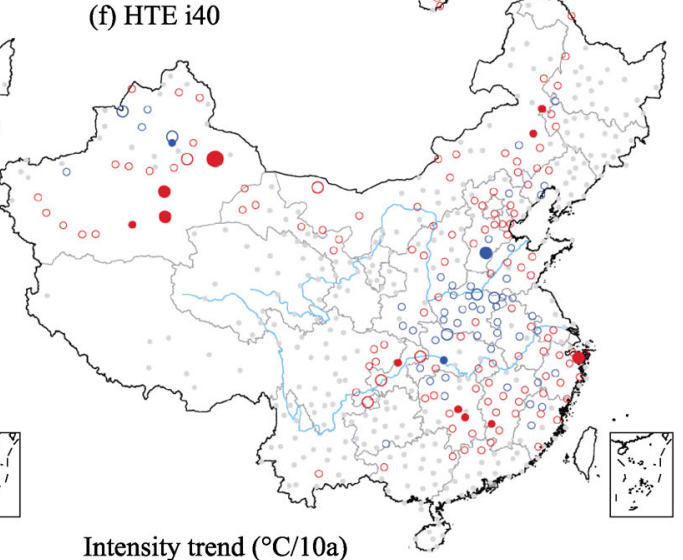

Intensity trend $\left({ }^{\circ} \mathrm{C} / 10 \mathrm{a}\right)$

$$
\begin{aligned}
& \circ-0.25--0.15 \circ-0.05-0 \circ 0.05-0.15 \\
& \circ-0.15--0.05 \circ 0-0.05 \circ 0.15-0.25
\end{aligned}
$$

Figure 3 Trends in HTE frequency (a, c, e; days/10a) and intensity (b, d, f; $\left.{ }^{\circ} \mathrm{C} / 10 \mathrm{a}\right)$ during 1961-2014

(Red circles $=$ increasing trends; blue circles $=$ decreasing trends; filled circles $=$ significant trends $(p<0.05)$; gray dots $=$ no trend or no data; three representative regions: I, northern China; II, central China; and III, southeastern coast).

detected at 9 stations in frequency, at 11 stations in intensity, and at 7 stations in both indices $(p<0.05)$. The strongest increasing trends were 1.15 days per decade for frequency and $0.17^{\circ} \mathrm{C}$ per decade for intensity. Decreasing trends were detected at 58 stations for frequency, at 55 stations for intensity, and at 47 stations for both indices. These stations were still 
mainly located in the mid-lower reaches of the Yellow River, but the extent shrank remarkably compared with those of HTE35 and HTE37. Among them, significant decreasing trends were detected at one station in both frequency and intensity $(p<0.05)$. The strongest decreasing trends were -0.34 days per decade for frequency and $-0.94^{\circ} \mathrm{C}$ per decade for intensity.

\subsection{Time series of frequency and intensity of HTEs}

Regional time series were investigated for entire China and three selected regions. The three representative regions were northern China (Region I), central China (Region II), and southeastern coast (Region III) (Figure 3a). They were all typical regions according to the bio-physical zonation of China; moreover, they were relatively homogeneous in occurrence and trends of HTEs. HTE35, HTE37, and HTE40 showed overall increasing trends in both frequency and intensity during 1961-2014 in northern China, southeast China, and entire China, while the HTEs decreased in central China (Figures 4 and 5). However, the LOESS curves largely displayed three-phase characteristics in HTEs; the phases were 1961-1980, the 1980s, and 1990-2014. To increase the reliability of statistical analyses, the linear slopes of frequency and intensity in four phases are given in Tables 1 and 2: 1961-1980, 1961-1990, 1990-2014, and 1961-2014.

At the national scale, HTE35, HTE37, and HTE40 increased in both frequency and intensity (Figures $4 \mathrm{a}, 4 \mathrm{~b}, 4 \mathrm{c}, 5 \mathrm{a}, 5 \mathrm{~b}$ and $5 \mathrm{c}$ ). The overall linear slopes of frequency and intensity were 0.425 day/10a $(p<0.05)$ and $0.022^{\circ} \mathrm{C} / 10 \mathrm{a}(p<0.1)$ for HTE35s and 0.24 day/10a $(p<0.05)$ and $0.013^{\circ} \mathrm{C} / 10 \mathrm{a}$ for HTE37. However, the changes in frequency and in intensity of both HTE35 and HTE37 (Figures 4a, 4b, 5a and 5b) were not homogeneous over time. Their LOESS curves were all "U" shaped and presented three stages: before 1980, the 1980s, and after 1990. During 1961-1980, both the frequency and intensity of HTE35 and HTE37 showed decreasing trends; from the period 1961-1980 to the period 1961-1990, the magnitude of those decreasing trends decreased; during 1990-2014, both the trends were positive (Tables 1 and 2). In contrast, HTE40 showed a slight increasing trend in frequency and intensity. HTE40 increased in both frequency and intensity consistently over the entire period.

In addition to the asymmetrical characteristics of the trends of HTEs over time, they also varied over space. The frequency and intensity of HTE35s increased by 1.04 day/10a $(p<0.01)$ and $0.04^{\circ} \mathrm{C} / 10 \mathrm{a}(p<0.05)$ in northern China, and by 1.34 day/10a $(p<0.01)$ and $0.03^{\circ} \mathrm{C} / 10 \mathrm{a}(p<0.05)$ in southeastern China (Tables 1 and 2$)$. In contrast, they decreased by -0.59 day $/ 10 \mathrm{a}$ and $-0.03^{\circ} \mathrm{C} / 10 \mathrm{a}$ in central China (Region II). In the three regions, the LOESS curves were all asymmetrical before and after the 1980s (Figures 4 and 5). The frequency of HTE35 showed no clear trend in northern China and southeastern China during 1961-1980, whilst increasing trends were observed during 1961-1990, and the trends were enhanced during 1990-2014 (Figures 4d and 4g). The intensity of HTE35 showed no clear trend and a decreasing trend in northern China (Region I) and southeastern coast (Region III) before 1990, respectively, whilst it showed increasing trends in both regions during 1990-2014 (Figures 5d and 5g). In central China, the frequency and intensity of HTE35 showed strong decreasing trends during 1961-1980, moderate decreasing trends during 1961-1990, and strong increasing trends during 1990-2014 (Figures 4j and 5j).

The frequency and intensity of HTE37 also varied over space and showed temporal 
asymmetry. They increased by 0.378 day $/ 10 \mathrm{a}$ and $0.016^{\circ} \mathrm{C} / 10 \mathrm{a}$ in northern China (Region I), and by 0.5 day/10a $(p<0.05)$ and $0.025^{\circ} \mathrm{C} / 10 \mathrm{a}(p<0.1)$ in the southeastern coast region $(\mathrm{Re}-$ gion III) (Tables 1 and 2). In contrast, they decreased by -0.423 day/10a $(p<0.01)$ and $-0.004^{\circ} \mathrm{C} / 10 \mathrm{a}$ in central China (Region II). In the three regions, the LOESS curves were all asymmetrical, and three phrases were detected (Figures $4 \mathrm{e}, 4 \mathrm{~h}, 4 \mathrm{k}, 5 \mathrm{e}, 5 \mathrm{~h}$ and $5 \mathrm{k}$ ). During 1961-1980, the frequency and intensity of HTE37 decreased in all the three regions, which are consistent with the trends for entire China (Tables 1 and 2). From the period 1961-1980 to 1961-1990, the decreasing trends in the frequency of HTE37 clearly dropped in magnitude in northern China (Region I) and central China (Region II), while it changed into an increasing trend in southeastern coast (Region III) (Table 1); the decreasing trends in intensity were largely constant in northern China and central China, while it changed into an increasing trend in southeastern China (Table 2). During 1990-2014, both the frequency and intensity of HTE37 increased in the three regions, which are consistent with the trends for entire China (Tables 1 and 2).

$35^{\circ} \mathrm{C}$

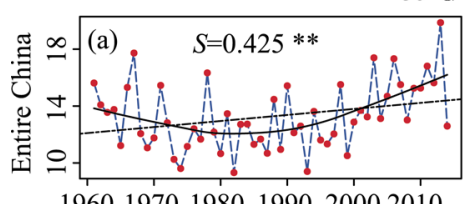

196019701980199020002010

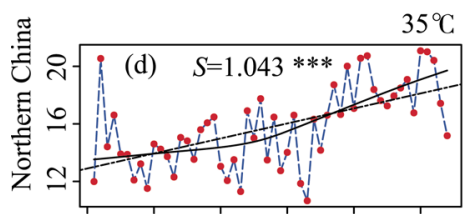

196019701980199020002010
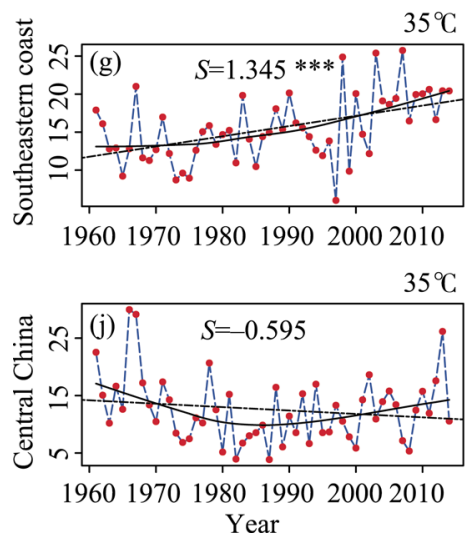

$37^{\circ} \mathrm{C}$

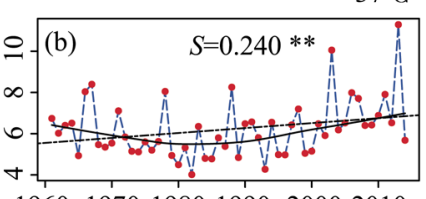

196019701980199020002010

$37^{\circ} \mathrm{C}$

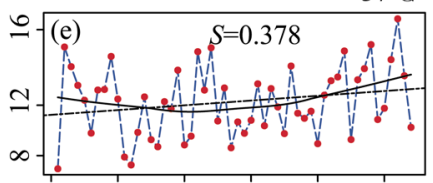

19701980199020002010

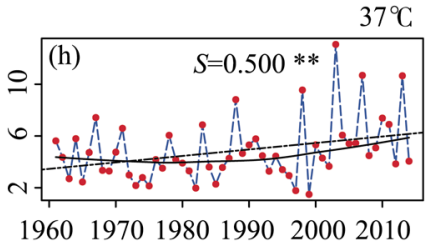

$37^{\circ} \mathrm{C}$

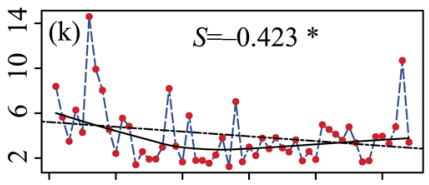

196019701980199020002010 Year

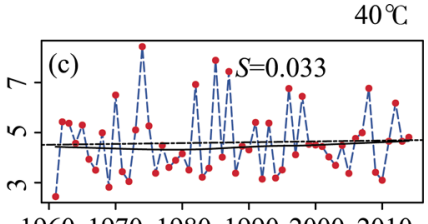

196019701980199020002010

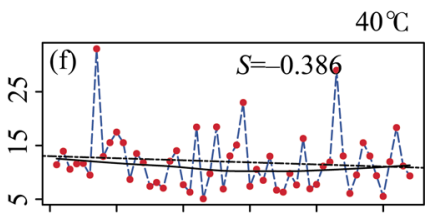

196019701980199020002010

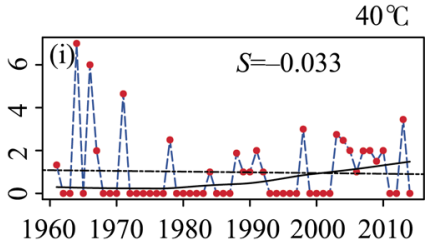

$40^{\circ} \mathrm{C}$

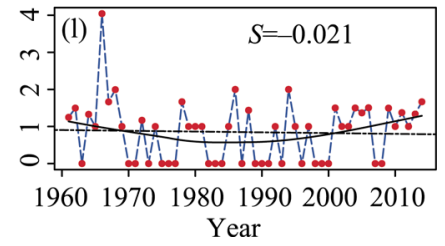

Figure 4 Time series of HTE frequency during 1961-2014 in entire China and three regions (S indicates the magnitude of a trend (days $/ 10 \mathrm{a}$ ); the trend significance is marked as $* p<0.1, * * p<0.05$, and $* * * p<0.01$ )

HTE40 decreased slightly in frequency for all three regions, while it had a weak decreasing trend in northern China (Region I), a significant increasing trend in southeastern coast (region III), and a weak increasing trend in central China (Region II) (Tables 1 and 2). Only northern China (Region I) had HTE40s every year in this period (Figure 4f); in contrast, neither central China (Region II) nor Southeastern Coast China (Region III) had continuous HTE40s over the 54 years (Figures $4 \mathrm{i}$ and 41). Nevertheless, the LOESS curves for HTE40 
Table 1 Trends of HTE frequency during 1961-2014 in entire China and representative regions (days/10a)

\begin{tabular}{|c|c|c|c|c|c|c|c|c|c|}
\hline & $1961-1980$ & $1961-1990$ & 1990-2014 & 1961-2014 & & 1961-1980 & $1961-1990$ & 1990-2014 & 1961-2014 \\
\hline \multicolumn{5}{|c|}{ Entire China } & \multicolumn{5}{|c|}{ Southeastern Coast } \\
\hline HTEf35 & $-1.455^{*}$ & -0.653 & $1.833^{* * *}$ & $0.425^{* *}$ & HTEf35 & -0.888 & 0.804 & $2.768 * *$ & $1.345^{* * *}$ \\
\hline HTEf37 & -0.665 & -0.321 & $0.947^{* *}$ & $0.240^{* *}$ & HTEf37 & -0.426 & 0.125 & 1.227 & $0.500^{* *}$ \\
\hline HTEf40 & 0.018 & 0.175 & 0.105 & 0.033 & HTEf40 & -1.068 & -0.571 & 0.370 & -0.033 \\
\hline \multicolumn{5}{|c|}{ Northern China } & \multicolumn{5}{|c|}{ Central China } \\
\hline HTEf35 & -0.078 & 0.020 & $2.059^{* * *}$ & $1.043^{* * *}$ & HTEf35 & $-5.326^{* *}$ & $-4.012^{* * *}$ & 2.068 & -0.595 \\
\hline HTEf37 & -1.195 & -0.357 & $1.25^{*}$ & 0.378 & HTEf37 & $-2.746^{* *}$ & $-1.742^{* * *}$ & $0.933^{*}$ & $-0.423^{*}$ \\
\hline HTEf40 & -2.492 & -0.684 & 1.451 & -0.386 & HTEf40 & -0.503 & $-0.345^{*}$ & $0.386^{* *}$ & -0.021 \\
\hline
\end{tabular}

Note: The trend significance is marked as $* p<0.1, * * p<0.05$, and $* * * p<0.01$.

Table 2 Trends of HTE intensity during 1961-2014 in entire China and representative regions $\left({ }^{\circ} \mathrm{C} / 10 \mathrm{a}\right)$

\begin{tabular}{|c|c|c|c|c|c|c|c|c|c|}
\hline & 1961-1980 & $1961-1990$ & 1990-2014 & 1961-2014 & & 1961-1980 & $1961-1990$ & 1990-2014 & $1961-2014$ \\
\hline \multicolumn{5}{|c|}{ Entire China } & \multicolumn{5}{|c|}{ Southeastern Coast } \\
\hline HTEi35 & -0.052 & $-0.048 *$ & $0.099 * * *$ & $0.022 *$ & HTEi35 & -0.061 & -0.02 & $0.116^{* *}$ & $0.033 * *$ \\
\hline HTEi37 & -0.041 & $-0.036^{*}$ & $0.061 *$ & 0.013 & HTEi37 & -0.037 & 0.021 & 0.049 & 0.025 \\
\hline HTEi40 & 0.046 & 0.005 & 0.019 & 0.015 & HTEi40 & -0.105 & -0.013 & $0.162 * *$ & $0.042 *$ \\
\hline \multicolumn{5}{|c|}{ Northern China } & \multicolumn{5}{|c|}{ Central China } \\
\hline HTEi35 & 0.011 & -0.008 & 0.071 & $0.042 * *$ & HTEi35 & -0.201 & $-0.164 * *$ & $0.152 * *$ & -0.025 \\
\hline HTEi37 & -0.013 & -0.018 & 0.041 & 0.016 & HTEi37 & -0.102 & $-0.131 * *$ & $0.132 * * *$ & -0.004 \\
\hline HTEi40 & -0.035 & -0.049 & 0.021 & -0.012 & HTEi40 & -0.135 & $-0.133 * *$ & 0.093 & 0.007 \\
\hline
\end{tabular}

Note: The trend significance is marked as $* p<0.1, * * p<0.05$, and $* * * p<0.01$.
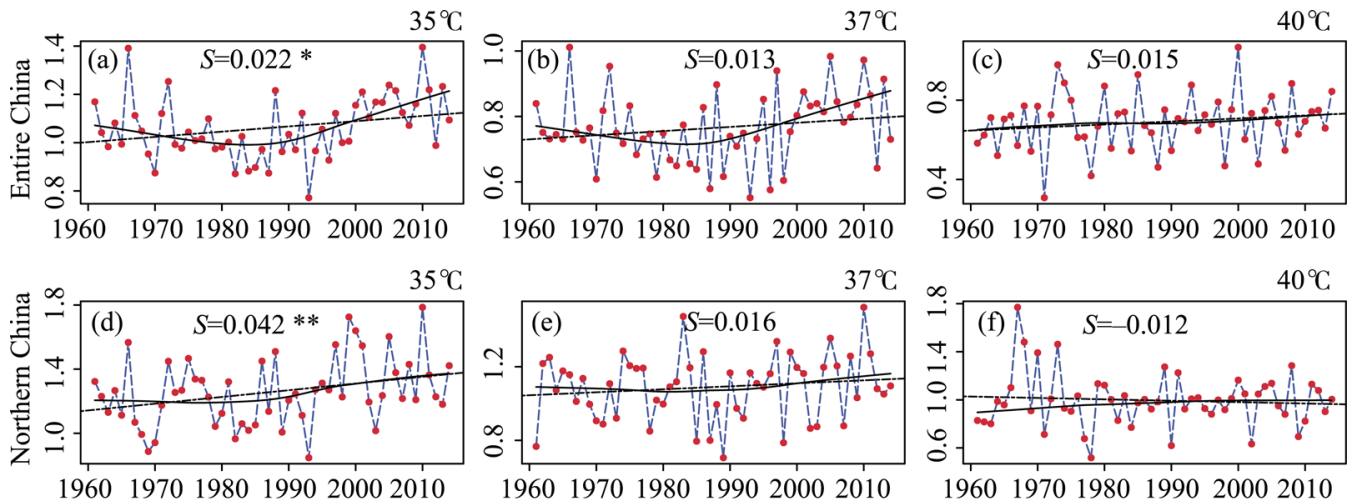

$35^{\circ} \mathrm{C}$

$37^{\circ} \mathrm{C}$
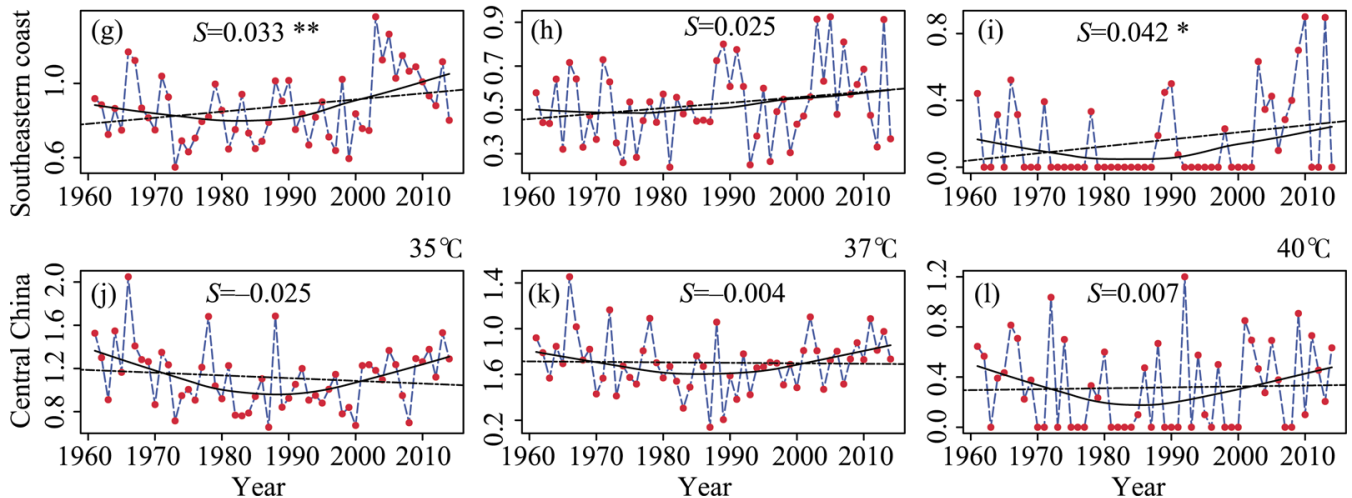

Figure 5 Time series of HTE intensity during 1961-2014 in entire China and three regions (S indicates the magnitude of a trend $\left({ }^{\circ} \mathrm{C} / 10 \mathrm{a}\right)$; the trend significance is marked as $* p<0.1, * * p<0.05$, and $\left.* * * p<0.01\right)$ 
were analogous to those for HTE35 and HTE37, showing asymmetry (Figures 4f, 4i, and 41, 5f, $5 \mathrm{i}$ and 51). During 1961-1980, both the frequency and intensity of HTE40 decreased in the three selected regions, while the magnitude of these decreasing trends significantly dropped from the period of 1961-1980 to 1961-1990 (Tables 1 and 2). During 1990-2014, both the frequency and intensity of HTE40 increased in the three regions, which are consistent with the trends for entire China.

\section{Discussion}

\subsection{Spatial heterogeneity in frequency and intensity of HTEs and their trends}

The present study investigated both spatial patterns and temporal trends in the frequency and intensity of HTE35, HTE37, and HTE40. Overall, the frequencies of HTEs were much higher in southeast and northwest China than in northern China; however, the HTEs in northern China had relatively high intensities, particularly HTE37s and HTE40s. The trends in both frequency and intensity largely coincided over space. In north and southeastern China, HTEs increased significantly in both frequency and intensity. In central China, a warming hole was found in the frequencies and intensities of HTEs. These results thus extend the understanding of patterns and trends of HTEs in previous studies, which mainly investigated the changes in frequencies of HTE35 (Ding et al., 2010; Sun et al., 2014; Zhai and Pan, 2003; Zhang et al., 2004) and in the 90th-percentile temperature (Piao et al., 2010; Wang et al., 2014b).

\subsection{Three phases in HTEs' trends}

Although clear spatial variations were found in the patterns and overall trends of HTEs, the HTEs overwhelmingly presented three-phase characteristics in all the three representative regions and throughout China; the phases were 1961-1979, 1980-1989, and 1990-2014. All the three HTEs overwhelmingly decreased in both frequency and intensity during 1961-1979 throughout China, and those decreasing trends dropped in magnitude or changed to increasing trends during 1961-1990. In contrast, all the three HTEs increased strongly in both frequency and intensity during 1990-2014 across China. Recently, several studies argued that global warming has slowed down since 1998, and this phenomenon was termed "hiatus" (Easterling and Wehner, 2009; Karl et al., 2015). Moreover, Li et al. (2015) demonstrated that China is experiencing a hiatus. However, HTEs have been increasing since 1990 without any pause across China, as indicated by the above results. This phenomenon may indicate that the slowdown in global warming (hiatus) does not decrease HTEs; this finding agrees with other studies (Donat et al., 2013; Seneviratne et al., 2014; Sillmann et al., 2014) that argued that no pause exists in the increase of HTES.

Additionally, strong increases in the frequency and intensity of HTEs were also detected during 1990-2014 even in central China. With the monotonic trends in this study indicated by the MK test and Sen's slope estimator, this region had decreasing trends (mainly insignificant) in both the frequency and intensity of HTEs, which was also in agreement with previous studies (Pan et al., 2013). From this perspective, central China had been called a "warming hole" region; such a phenomenon had also been found in other countries, e.g., 
USA (Donat et al., 2013; Meehl et al., 2012). However, the regional time series indicated obvious temporal asymmetries in the trends in both frequency and intensity of HTEs in central China. The time series of frequency and intensity of HTEs were all "U" shaped and presented three stages: before 1980, the 1980s, and after 1990. The three-phase characteristics and strong increasing trends in HTEs during the hiatus period have not yet reported in "warming hole" areas. This phenomenon should be paid further attention, and further studies are needed to reveal the mechanism underlying this phenomenon.

\subsection{Potential impacts and possible causes of the recently increasing trends in HTEs}

The strong increases in both the frequency and intensity of HTEs should be paid further attention as this phenomenon may cause various impacts on human society and the ecosystem (Deng et al., 2011; Reichstein et al., 2013). As a semiarid region, northern China experienced clear deforestation and desertification in the past decades (Liu and Wang, 2011), which would probably enhance HTEs via a decrease in the evaporative cooling effect and increase in incoming shortwave solar radiation (Charney, 1975). The enhanced HTEs, in turn, may exacerbate the degradation of the ecosystem (Reichstein et al., 2013). Such feedback would also probably have negative impacts on water resources and agricultural productivity (Piao et al., 2010). In southeastern China, the strongest increasing trends in the frequency and intensity of HTEs spatially coincided with the most rapidly urbanizing areas. This region has been experiencing rapid urbanization since the implementation of reform and opening up policy in 1978 (Du et al., 2015; Small and Elvidge, 2013). The urban heat islands (UHI) effect has been argued to enhance HTEs in this region (Sun et al., 2014). Additionally, studies also found that this region has a significant increasing trend in precipitation (Shi et al., 2014). The coincidence of increases in HTEs and humidity in such rapidly urbanizing and densely populated areas would likely cause more severe impacts on society, ranging from human health (Xie et al., 2015), energy consumption (Davis and Gertler, 2015), labor productivity (Zander et al., 2015), to economic growth (Dell et al., 2014).

However, the mechanism for the three-phase phenomenon in HTEs remains unclear. Future studies should focus on the transition mechanisms. A probable mechanism is the enhanced UHI associated with accelerated urbanization across China (Sun et al., 2014). Possible mechanisms also include changes in atmospheric circulation (Coumou et al., 2015), El Niño/Southern Oscillation (Wang et al., 2014a), and planetary waves (Cohen et al., 2014).

Additionally, inhomogeneity may influence the reliability of the results and findings. The surface air temperature dataset used in this study was obtained from the China Meteorological Data Sharing Service System. Some of the meteorological stations have been relocated or their surrounding condition has been changed during rapid urbanization, which may cause the data inhomogeneity. However, the quality of the meteorological dataset was firmly controlled before its release for public use through procedures including the climatological limit check, the station or regional extremes check, the internal consistency check, and the temporal and spatial consistency checks, etc. (Zhang et al., 2011). Following previous studies (e.g., Zhai and Pan, 2003; Zhang et al., 2004, 2011; Liu and Wang, 2011), we did not apply further homogeneity adjustment to this dataset. Although previous adjustment to the temperature dataset before its release can ensure the reliability of our results to a certain extent, 
we still think benchmarking of methods is needed in future studies for a strict data homogenization (Li et al., 2015).

\section{Conclusions}

This paper presented the spatial patterns and temporal trends in the frequency and intensity of HTEs at 494 stations across China during 1961-2014. HTEs happened throughout China except for the mountainous and elevated southwestern part (Tibet, Qinghai, west Sichuan and Yunnan). HTE35, HTE37, and HTE40 respectively occurred in $82 \%, 71 \%$, and 37\% of the surveyed stations, with an average frequency of more than once per year at $57.89 \%$, $34.82 \%$, and $2.43 \%$ of the stations. Overall, the frequency of HTEs was much higher in southeast and northwest China than in northern China; however, HTEs in northern China had relatively high intensities, particularly HTE37s and HTE40s. China is therefore prone to HTEs, particularly in the humid southeastern region and the semiarid/arid areas in northwest China.

Moreover, the impacts of HTEs would likely exacerbate as the increasing trends were found in both frequency and intensity of the HTEs. Frequency and intensity of all three HTEs increased during 1961-2014 for China as a whole, with a trend ranging from 0.425 to 0.033 days/10a for frequency and from 0.022 to $0.015{ }^{\circ} \mathrm{C} / 10 \mathrm{a}$ for intensity. The increasing trends in HTE35 and HTE37 were stronger for southeastern coast and northern China than the overall trend for China. For China and the representative regions, the fastest increases in both frequency and intensity occurred during 1990-2014; in contrast, both frequency and intensity of HTEs overwhelmingly decreased during 1961-1990, which made the time series of HTEs were "U-shaped". Such increasing trends would likely increase drought risk and challenge the health and sustainability of both human society and ecosystem, particularly because the strongest increasing trends were detected in southeastern China with rapid urbanization and in the arid/semiarid northern China. Further studies are needed to elucidate the exact mechanism underlying the HTEs and their changes.

Additionally, a "warming hole" was found in central China, which showed decreasing trends in both frequency and intensity of HTEs during 1961-2014. However, all the three HTEs increased strongly in both frequency and intensity during 1990-2014 in this region; in contrast, both frequency and intensity of HTEs decreased significantly during 1961-1990. The "warming hole" region in 1961-1990 changed into an area that experienced rapid increase in HTEs during 1990-2014. Such a finding implied that temporal scale is vital for understanding the trends in HTEs and the existence of the "warming hole" phenomena. A time-series analysis may be also necessary for other "warming hole" regions (Donat et al., 2013). So this "warming hole" phenomenon needs to be further discussed and explored in the future.

\section{References}

Alexander L V, Zhang X, Peterson T C et al., 2006. Global observed changes in daily climate extremes of temperature and precipitation. Journal of Geophysical Research: Atmospheres, 111(D5): D05109.

Charney J G, 1975. Dynamics of deserts and drought in the Sahel. Quarterly Journal of the Royal Meteorological 
Society, 101(428): 193-202.

China Meteorological Administration (CMA), 2008. Warning signals: High temperature warning signals were classified into three grades. Beijing: China Meteorological Administration.

Cleveland W S, 1979. Robust locally weighted regression and smoothing scatterplots. Journal of the American Statistical Association, 74(368): 829-836.

Cohen J, Screen J A, Furtado J C et al., 2014. Recent Arctic amplification and extreme mid-latitude weather. Nature Geoscience, 7(9): 627-637.

Coumou D, Lehmann J, Beckmann J, 2015. The weakening summer circulation in the Northern Hemisphere mid-latitudes. Science, 348(6232): 324-327.

Davis L W, Gertler P J, 2015. Contribution of air conditioning adoption to future energy use under global warming. Proceedings of the National Academy of Sciences, 112(19): 5962-5967.

Dell M, Jones B F, Olken B A, 2014. What do we learn from the weather? The new climate-economy literature. Journal of Economic Literature, 52(3): 740-798.

Deng H, Zhao F, Zhao X, 2012. Changes of extreme temperature events in Three Gorges area, China. Environmental Earth Sciences, 66(7): 1783-1790.

Ding T, Qian W, Yan Z, 2010. Changes in hot days and heat waves in China during 1961-2007. International Journal of Climatology, 30(10): 1452-1462.

Donat M G, Alexander L V, Yang $\mathrm{H}$ et al., 2013. Global land-based datasets for monitoring climatic extremes. Bulletin of the American Meteorological Society, 94(7): 997-1006.

Du S, Van Rompaey A, Shi P et al., 2015. A dual effect of urban expansion on flood risk in the Pearl River Delta (China) revealed by land-use scenarios and direct runoff simulation. Natural Hazards, 77(1): 111-128.

Easterling D R, Wehner M F, 2009. Is the climate warming or cooling? Geophysical Research Letters, 36(8): L08706.

Hansen J, Sato M, Ruedy R, 2012. Perception of climate change. Proceedings of the National Academy of Sciences, 109(37): E2415-E2423.

Hou W, Yu C, Ying L et al., 2014. Climatic characteristics over China in 2013. Meteorologica Monthly, 40(4): 482-493. (in Chinese)

IPCC, 2012. Managing the risks of extreme events and disasters to advance climate change adaptation. A Special Report of Working Groups I and II of the Intergovernmental Panel on Climate Change. Cambridge, UK and New York, NY: Cambridge University Press. 582.

Jones P D, Hulme M, 1996. Calculating regional climatic time series for temperature and precipitation: Methods and illustrations. International Journal of Climatology, 16(4): 361-377.

Karl T R, Arguez A, Huang B et al., 2015. Possible artifacts of data biases in the recent global surface warming hiatus. Science, 348(6242): 1469-1472.

Kendall M, 1975. Rank Correlation Methods. London: Grif.

Li Q, Yang S, Xu W et al., 2015. China experiencing the recent warming hiatus. Geophysical Research Letters, 42(3): 889-898.

Liu G L, Zhang L C, He B et al., 2015. Temporal changes in extreme high temperature, heat waves and relevant disasters in Nanjing metropolitan region, China. Natural Hazards, 76(2): 1415-1430.

Liu S, Wang T, 2011. Climate change and local adaptation strategies in the middle Inner Mongolia, northern China. Environmental Earth Sciences, 66(5): 1449-1458.

Mann H B, 1945. Nonparametric tests against trend. Econometrica, 13(3): 245-259.

Meehl G A, Arblaster J M, Branstator G, 2012. Mechanisms contributing to the warming hole and the consequent U.S. east-west differential of heat extremes. Journal of Climate, 25(18): 6394-6408.

Pan Z, Wan B, Gao Z, 2013. Asymmetric and heterogeneous frequency of high and low record-breaking temperatures in China as an indication of warming climate becoming more extreme. Journal of Geophysical Research: Atmospheres, 118(12): 6152-6164.

Peterson T C, Zhang X, Brunet-India M et al., 2008. Changes in North American extremes derived from daily 
weather data. Journal of Geophysical Research: Atmospheres, 113(D7): D07113.

Piao S, Ciais P, Huang Y et al., 2010. The impacts of climate change on water resources and agriculture in China. Nature, 467(7311): 43-51.

Portmann R W, Solomon S, Hegerl G C, 2009. Spatial and seasonal patterns in climate change, temperatures, and precipitation across the United States. Proceedings of the National Academy of Sciences, 106(18): 7324-7329.

Reichstein M, Bahn M, Ciais P et al., 2013. Climate extremes and the carbon cycle. Nature, 500(7462): $287-295$.

Robine J-M, Cheung S L K, Le Roy S et al., 2008. Death toll exceeded 70,000 in Europe during the summer of 2003. Comptes Rendus Biologies, 331(2): 171-178.

Sen P K, 1968. Estimates of the regression coefficient based on Kendall's Tau. Journal of the American Statistical Association, 63(324): 1379-1389.

Seneviratne S I, Donat M G, Mueller B et al., 2014. No pause in the increase of hot temperature extremes. Nature Climate Change, 4(3): 161-163.

Shi J, Wen K, Cui L, 2016. Distribution and trend on consecutive days of severe weathers in China during 1959-2014. Journal of Geographical Sciences, 26(6): 658-672.

Shi P, Sun S, Wang M et al., 2014. Climate change regionalization in China (1961-2010). Science China Earth Sciences, 57(11): 2676-2689.

Sievers G L, 1978. Weighted Rank Statistics for Simple Linear Regression. Journal of the American Statistical Association, 73(363): 628-631.

Sillmann J, Donat M G, Fyfe J C et al., 2014. Observed and simulated temperature extremes during the recent warming hiatus. Environmental Research Letters, 9(6): 064023.

Small C, Elvidge C D, 2013. Night on Earth: Mapping decadal changes of anthropogenic night light in Asia. International Journal of Applied Earth Observation and Geoinformation, 22: 40-52.

Sun Y, Zhang X, Zwiers F W et al., 2014. Rapid increase in the risk to extreme summer heat in eastern China. Nature Climate Change, 4(12): 1082-1085.

Wang W, Zhou W, Chen D, 2014a. Summer high temperature extremes in Southeast China: Bonding with the El Niño-Southern Oscillation and East Asian summer monsoon coupled system. Journal of Climate, 27(11): 4122-4138.

Wang X L, Swail V R, 2001. Changes of extreme wave heights in Northern Hemisphere Oceans and related atmospheric circulation regimes. Journal of Climate, 14(10): 2204-2221.

Wang Y, Ren F, Zhang X, 2014b. Spatial and temporal variations of regional high temperature events in China. International Journal of Climatology, 34(10): 3054-3065.

Wu Y J, Wu S Y, Wen J H et al., 2016. Changing characteristics of precipitation in China during 1960-2012. International Journal of Climatology, 36(3): 1387-1402.

Xie P, Wang Y, Liu Y et al., 2015. Incorporating social vulnerability to assess population health risk due to heat stress in China. Acta Geographica Sinica, 70(7): 1041-1051. (in Chinese)

Zander K K, Botzen W J W, Oppermann E et al., 2015. Heat stress causes substantial labour productivity loss in Australia. Nature Climate Change, 5(7): 647-651.

Zhai P, Pan X, 2003. Trends in temperature extremes during 1951-1999 in China. Geophysical Research Letters, 30(17): 1913.

Zhang Q, Li J, David Chen Y et al., 2011. Observed changes of temperature extremes during 1960-2005 in China: Natural or human-induced variations? Theoretical and Applied Climatology, 106(3): 417-431.

Zhang S Y, Song Y L, Zhang D K et al., 2004. The climatic characteristics of high temperature and the assessment method in the large cities of northern China. Acta Geographica Sinica, 59(3): 383-390. (in Chinese)

Zhang X, Alexander L, Hegerl G C et al., 2011. Indices for monitoring changes in extremes based on daily temperature and precipitation data. Wiley Interdisciplinary Reviews: Climate Change, 2(6): 851-870.

Zhou L, Dickinson R E, Tian Y et al., 2004. Evidence for a significant urbanization effect on climate in China. Proceedings of the National Academy of Sciences, 101(26): 9540-9544. 